\title{
ENTRE LA IGUALDAD \\ Y LA GOBERNABILIDAD: \\ LOS MOTIVOS DE LA SUPRESIÓN \\ DEL FUERO ECLESIÁSTICO*
}

\author{
Pablo Mijangos y González \\ Centro de Investigación y Docencia Económicas
}

$\mathrm{E}_{\text {volución de Ayutla promulgó un decreto para el arreglo }}^{123 \text { de noviembre de } 1855 \text {, el gobierno nacido de la re- }}$ provisional de la "administración de justicia en la nación", elaborado e impulsado por el nuevo ministro de Justicia y Negocios Eclesiásticos, Benito Juárez. Conocido a partir de entonces como "Ley Juárez", el decreto en cuestión se inscribía en una larga tradición de reformas legislativas al Poder Judicial Federal, pues en su mayor parte estaba dedicado a reconfigurar la estructura y competencias de la Suprema Corte de Justicia, los tribunales de circuito y los juzgados de distrito, así como al establecimiento de un tribunal superior

Fecha de recepción: 10 de mayo de 2015

Fecha de aceptación: 22 de junio de 2015

\footnotetext{
"Agradezco los comentarios y sugerencias de María del Refugio González, Ángeles Estrada y Javier Mijangos a una primera versión de este ensayo. Doy gracias también a Erika Gómez por su ayuda para transcribir varios expedientes del Archivo Central de la Suprema Corte de Justicia de la Nación.
} 
para el Distrito Federal. En el capítulo de “disposiciones generales”, sin embargo, el decreto incluía dos artículos que iban más allá del arreglo de la judicatura federal y rompían definitivamente el precario equilibrio entre la Iglesia y el Estado. El artículo 42, en efecto, anunciaba la supresión de los tribunales especiales - como los de comercio y mineríay disponía que, en lo sucesivo, los tribunales eclesiásticos cesarían de resolver "negocios civiles” y sólo continuarían conociendo de "los delitos comunes de los individuos de su fuero, mientras se expide una ley que arregle ese punto”. Un poco más adelante, el artículo 44 aclaraba que el fuero eclesiástico en los delitos comunes sería renunciable, esto es, que los reos pertenecientes al clero tendrían derecho a escoger si su juicio sería llevado ante los tribunales civiles o ante los eclesiásticos. El decreto establecía un arreglo similar para los tribunales militares y aclaraba que, por tratarse de disposiciones generales para toda la República, este nuevo régimen no podría ser modificado por los estados. ${ }^{1}$

La Ley Juárez provocó un fuerte terremoto político de manera inmediata. Al día siguiente de su publicación, los magistrados de la Suprema Corte manifestaron al gobierno que una modificación tan grave del sistema judicial requería de una discusión amplia y cuidadosa, y que en esa medida el ministro de Justicia tendría que haberlos consultado y escuchado previamente, como era costumbre. En lugar de contestarles, Juárez destituyó a los magistrados y procedió al nombramiento de nuevos miembros para el máximo

1 "Ley de Administración de Justicia y Orgánica de los Tribunales de la Federación”, en Documentos básicos de la Reforma, t. I, pp. 82-89. Sobre la reforma de 1855 al Poder Judicial Federal, véase LóPEz GonzÁLEz, La organización para la administración de la justicia, pp. 63-81. 
tribunal del país (aprovechando la facultad que para ello le concedía el artículo 48 de la nueva ley). ${ }^{2}$ Poco después, el arzobispo de México y sus sufragáneos de toda la República publicaron una serie de protestas contra la Ley Juárez, en las que denunciaban los artículos 42 y 44 como violatorios de las leyes generales de la Iglesia y exigían su suspensión mientras se negociaba una salida mutuamente aceptable con la Santa Sede. De nueva cuenta, Juárez declinó dar mayor explicación sobre las razones de su decreto y recordó a los obispos que no era conveniente al "decoro y dignidad" del gobierno "entrar en discusión con algunos de sus súbditos sobre el cumplimiento o desobedecimiento [de las leyes]". ${ }^{3}$ Para ese momento el influyente gobernador de Guanajuato, Manuel Doblado, ya había decidido romper la frágil coalición gobernante y se había pronunciado al grito de "religión y fueros", precipitando la renuncia del presidente Juan Álvarez y facilitando el ascenso de los liberales moderados bajo el liderazgo del ministro de Guerra, Ignacio Comonfort. ${ }^{4}$ Benito Juárez renunció a su cargo el 9 de diciembre pero pudo volver a Oaxaca como gobernador interino.

Significativamente, el nuevo gobierno instalado en diciembre de 1855 prometió actuar con "toda la circunspección y detenimiento" en los asuntos eclesiásticos, pero no derogó la Ley Juárez. ${ }^{5}$ El propio Manuel Doblado reconoció que su pronunciamiento había sido desproporcionado

\footnotetext{
${ }^{2}$ Arnold, Política y justicia, pp. 158-161.

3 Véase Tamayo, Benito Juárez, t. 2, cap. VI, docs. 18-27, 33-34.

${ }^{4}$ Roeder, Juárez y su México, pp. 187-188; González Navarro, "La Ley Juárez”, pp. 958-959.

5 "Manifiesto de los ministros de Estado a la Nación, 22 de diciembre de 1855”, Documentos básicos de la Reforma, t. I, p. 91.
} 
y pasó rápidamente de crítico a entusiasta defensor del decreto del 23 de noviembre. ${ }^{6}$ ¿Por qué decidieron los moderados sostener y respaldar la medida más polémica de sus predecesores? A juzgar por los editoriales de la prensa liberal publicados durante las semanas posteriores a la promulgación de la Ley Juárez, una posible explicación es que este decreto se convirtió rápidamente en el símbolo y la primera realización de uno de los anhelos más profundos del credo liberal: la igualdad ante la ley. El Monitor Republicano, por citar uno entre muchos ejemplos similares, aplaudió la abolición de los fueros en materia civil como "un acto de verdadera justicia, porque no la hay para que en negocios de una misma clase y naturaleza, los ciudadanos sean juzgados por jueces distintos". ' Este argumento se enarboló una y otra vez frente a las críticas de la prensa conservadora, y adquirió mayor fuerza conforme se fue acrecentando la polarización del debate público. Sin ir más lejos, en abril de 1856, los miembros de la Comisión de Justicia del recién instalado Congreso Constituyente propusieron incorporar las disposiciones generales de la Ley Juárez al texto constitucional porque éstas representaban "un gran paso hacia la igualdad social” y eran profundamente consecuentes con "los principios democráticos". ${ }^{8}$

Aunque la identificación entre la Ley Juárez y el principio de igualdad ante la ley se convertiría en un lugar común del discurso y la historiografía liberales, una lectura serena y cuidadosa del decreto revela que éste sólo suprimió

6 Roeder, Juárez y su México, pp. 189-190.

7 “Editorial. Administración de justicia”, El Monitor Republicano (27 nov. 1855).

8 Reyes Heroles, El liberalismo mexicano, t. III, pp. 46-47. 
parciamente los fueros privilegiados. El primero en advertir esto fue el renombrado periodista y abogado liberal Juan Bautista Morales, quien, tratando de apaciguar los ánimos de la opinión clerical, señaló que la Ley Juárez, lejos de restringir los privilegios del clero, le había concedido a los eclesiásticos un derecho del que no gozaban los reos ordinarios ni tenían tampoco los clérigos antes de 1855: la facultad de "elegir el juez que quieran en los delitos comunes". 9 Años más tarde, Blas José Gutiérrez calificaría la Ley del 23 de noviembre de 1855 como "moderada" e "incompleta", y Francisco Bulnes rechazaría darle a Juárez el título de "iniciador de la abolición de los fueros militar y eclesiástico en nuestro país". ${ }^{10}$ De hecho, el propio Benito Juárez admitiría en sus memorias póstumas, los célebres Apuntes para mis bijos, que su ley reformista de 1855 había sido "imperfecta", ya que se había elaborado sin "proponer, discutir y acordar en el seno del gabinete un plan general” y porque se limitó a "extinguir el fuero eclesiástico en el ramo civil [...] dejándolo subsistente en materia criminal". ${ }^{11}$ ¿Se trató entonces de una ley moderada que fue mal leída tanto por sus simpatizantes como por sus detractores?

Desde su promulgación en 1855, la Ley Juárez ha sido un texto con frecuencia invocado pero escasamente entendido: un verdadero símbolo cuyo significado se presume - "la chispa que desató el incendio de la Reforma” y el primer

9 Juan Bautista Morales, "Amplio examen de la ley sobre administración de justicia expedida por Juárez”, en TAMAYo, Benito Juárez, t. 2, cap. VI, doc. 28.

10 Blas Gutiérrez, Leyes de Reforma, pp. 817-18; Bulnes, Juárez y las revoluciones, p. 156.

${ }^{11}$ JuÁrez, “Apuntes para mis hijos”, en Antología, p. 37. 
"desafío" a las "clases privilegiadas", en palabras de Juárez $-{ }^{12}$ pero cuyo surgimiento y objetivos distan mucho de ser comprendidos. ¿Por qué era tan urgente acabar con el fuero eclesiástico? ¿La ley era sólo un manifiesto en favor de la igualdad o era también una medida de gobierno que obedecía a problemas y objetivos más tangibles? El propósito del presente ensayo consiste en reconstruir las posibles motivaciones prácticas (y no sólo ideológicas) que llevaron a Benito Juárez a redactar este polémico decreto, considerando el largo debate sobre la viabilidad de los fueros en un orden republicano y, sobre todo, la experiencia efectiva del régimen de privilegios jurisdiccionales durante la primera mitad del siglo xix. La premisa central que guía esta reconstrucción es que el ataque a los fueros privilegiados debe analizarse en su contexto original, es decir, como parte de una ley que buscaba crear las condiciones básicas para el ejercicio de la "potestad pública" en el ámbito jurisdiccional. Es por ello que centraremos nuestra atención en las distintas maneras en que el fuero eclesiástico se había convertido en un obstáculo mayor para la administración de justicia, y, por lo tanto, en una verdadera amenaza para la gobernabilidad del país. Como veremos a continuación, la Ley Juárez fue mucho más que la realización - parcial o simbólicade un viejo principio liberal: a la luz de la historia judicial del México republicano, la supresión de los fueros aparece como una respuesta impostergable a problemas heredados del orden colonial y, sobre todo, como un remedio a la debilidad, ineficacia y escasa legitimidad del Estado.

12 JuÁrez, “Apuntes para mis hijos”, en Antología, p. 38. 
Para entender la magnitud de los cambios introducidos por la Ley Juárez, es necesario recordar que a mediados del siglo xIx, la Iglesia católica seguía ejerciendo plena potestad jurisdiccional por medio de su extensa red de juzgados eclesiásticos, vicarías y provisoratos. ${ }^{13}$ Mediante sus tribunales, la Iglesia no sólo intervenía en asuntos estrictamente relacionados con la disciplina eclesiástica y la salvación de las almas, sino en un amplio universo de causas criminales, familiares y civiles, en las que se disputaban toda clase de intereses y agravios terrenales. No resulta sencillo delimitar con precisión la competencia de los tribunales eclesiásticos, pero podría decirse que la jurisdicción de la Iglesia se definía o bien en función de la materia objeto del litigio, o bien en función de las personas involucradas. El primer tipo de causas comprendía las "causas espirituales y sus anexas", es decir, aquellas relacionadas con la administración de los

${ }_{13}$ Dejando a un lado los tribunales del clero regular, cuya jurisdicción estaba restringida a los asuntos disciplinarios de las órdenes religiosas masculinas, los principales tribunales de la Iglesia eran los siguientes: en primer lugar, la Audiencia eclesiástica o Provisorato, que estaba a cargo de todos los casos ordinarios de la jurisdicción eclesiástica y cuya sede se encontraba en la capital episcopal; en segundo, el Juzgado de Testamentos, Capellanías y Obras Pías, el cual, como su nombre lo indica, estaba especializado en dicha clase de asuntos; en tercer lugar, los juzgados eclesiásticos locales, a cargo de párrocos autorizados para dirimir causas no graves; y en cuarto y último, los vicarios foráneos, quienes vigilaban el cumplimiento de los preceptos eclesiásticos en ciertas demarcaciones y ejercían también una jurisdicción delegada por el obispo. El Tribunal del Santo Oficio había sido abolido en 1820 . Al respecto, véase Rubial et al., La Iglesia en el México colonial, pp. 77-80, y Traslosheros, Historia judicial eclesiástica, pp. 27-30. 
sacramentos, el culto divino, las obras piadosas y el ejercicio de las potestades que Jesucristo atribuyó en exclusiva a los apóstoles y sus sucesores: asuntos relacionados, por ejemplo, con los requisitos y efectos del sacramento del matrimonio, los votos y profesiones religiosas, los beneficios eclesiásticos, el juramento, los ritos sagrados, la obligación de pagar el diezmo, las disposiciones piadosas en los testamentos, la concesión o denegación de la sepultura eclesiástica, y los delitos contra la fe y la religión (blasfemia, herejía, sacrilegio, simonía, etcétera). ${ }^{14}$

En términos generales, la jurisdicción eclesiástica sobre estas materias era ampliamente reconocida, si bien era frecuente que los jueces civiles asumieran el conocimiento de litigios donde el carácter "espiritual" de los bienes o derechos en disputa no era tan claro, y que los tribunales superiores de los estados y la federación terminaran resolviendo esta clase de dudas competenciales por medio de los "recursos de fuerza y protección”. Desde tiempos de las reformas borbónicas, una exigencia constante de las autoridades civiles y los litigantes laicos era que todo aquello que pudiera ser "materia u objeto de un juicio temporal" fuera gobernado y decidido sólo por "los jueces y leyes temporales”, pues la jurisdicción debía regirse exclusivamente por "la naturaleza misma de las cosas". ${ }^{15} \mathrm{El}$ gran problema de la jurisdicción eclesiástica era precisamente que sus alcances no se limitaban a las materias puramente "espirituales y anexas”, pues los tribunales de la Iglesia también tenían

${ }_{14}$ Donoso, Instituciones de derecho canónico americano, t. III, pp. 247251; “Jurisdicción”, en Diccionario de derecho canónico, pp. 702-703.

${ }^{15}$ Curia Filípica Mexicana, pp. 30-34. 
competencia en función de la "diferente calidad de las personas contendientes". Esta segunda clase de jurisdicción era la relacionada con el llamado "fuero eclesiástico", el cual se definía genéricamente como el privilegio de los clérigos de "no poder ser reconvenidos, acusados ni castigados sino ante sus propios jueces y prelados”. ${ }^{16}$ Dicho privilegio se gozaba tanto en la materia civil como en la criminal, si bien en esta última existían reglas y procedimientos especiales tratándose de delitos graves o "atroces".

Gracias al fuero o "inmunidad” personal, los tribunales de la Iglesia podían abarcar un espectro de causas mucho más amplio que el de los temas estrictamente espirituales, pues bastaba que el demandado fuera un clérigo para que un asunto cayera en manos del juez eclesiástico. El excelente estudio de Berenise Bravo sobre el provisorato del arzobispado de México durante la gestión episcopal de Manuel Posada y Garduño (1840-1846) permite hacernos una idea del número y tipo de causas que entraban a los tribunales del clero por esta vía. Según demuestra la autora, en un periodo de apenas seis años el provisorato recibió 192 denuncias contra eclesiásticos en funciones, lo cual significa que casi $34 \%$ de los clérigos del arzobispado estuvo involucrado en un asunto judicial. ${ }^{17}$ De las 192, sabemos que 78 fueron clasificadas como causas criminales y 53 como civiles. Entre las primeras destacan las denuncias por propinar injurias, golpes y malos tratos a los feligreses, así como por el cobro excesivo de aranceles parroquiales; entre las

${ }^{16}$ J. M. Gutiérrez, Adiciones a la Librería de Escribanos, p. 156; Donoso, Instituciones de derecho canónico americano, t. I, p. 103.

17 Bravo, La gestión episcopal de Manuel Posada, pp. 121-161. 
segundas sobresalen las “causas por pesos": litigios provocados por adeudos contraídos por medio de préstamos, arrendamientos o servicios, o bien por el mal manejo de bienes de cofradías y legados píos. Es decir, se trata en su mayor parte de problemas de la vida cotidiana que la Iglesia gestionaba judicialmente con una doble finalidad: por un lado, el fuero les permitía a los obispos tener mayor control de la conducta y disciplina de sus clérigos; por el otro, el fuero también les servía para subrayar la identidad del clero como un "cuerpo" especial, cuyos miembros no debían ser mezclados indistintamente con el pueblo ordinario en los juzgados civiles.

Como reconoció el obispo fray Antonio de San Miguel en su célebre representación al rey de España de 1799, el fuero personal era "la bula de oro o carta magna de la nobleza y libertades de cada individuo del estado eclesiástico”, un privilegio fundamental del que dependía "esencialmente la consideración individual de los ministros de la Iglesia”. ${ }^{18} \mathrm{La}$ Santa Sede consideraba prioritaria la preservación del fuero y por ello había creado desde el siglo XviI un dicasterio dedicado única y exclusivamente a la defensa de las inmunidades y jurisdicción del clero, una tarea que también había sido encomendada enfáticamente a los obispos y a los príncipes católicos por la sesión 25, capítulo XX, del Concilio de Trento. ${ }^{19}$ Dicha misión, sin embargo, enfrentaba muchos y variados obstáculos, siendo el principal de ellos que el fuero distaba de ser una institución de origen divino, cuyas

18 Citada en PEÑA, Lecciones de práctica forense, pp. 439-440.

19 Del Re, La Curia Romana, pp. 373-375; El sacrosanto y ecuménico Concilio de Trento, pp. 415-417. 
inconfundibles raíces en el Evangelio pudieran ser esgrimidas como argumento incontestable frente a los poderes terrenales interesados en suprimirlo. El renombrado canonista chileno José Justo Donoso, por ejemplo, admitía que la inmunidad personal del clero no debía ser vista "como establecida y prescripta por derecho divino", aun cuando había sido reconocida por todas "las constituciones de los príncipes cristianos, principiando desde Constantino". ${ }^{20}$ Tal vez la defensa más audaz del fuero era la que proponía el obispo michoacano Clemente de Jesús Munguía al considerarlo un derecho natural de la Iglesia en tanto "sociedad perfecta":

La Iglesia es una sociedad visible, como lo confiesa todo católico, y en clase de tal, no puede faltarla ninguno de los atributos constitutivos de la sociedad. Sus miembros, relacionados por la profesión de una misma fe, la percepción de unos mismos sacramentos y la sumisión a una misma ley, son los fieles esparcidos por el orbe: su legislación es el Decálogo y los cánones que ha dado ella: su autoridad es el papa y todo el episcopado. No puede concebirse la Iglesia sin un poder de dar, ejecutar y aplicar las leyes dentro de los límites de su objeto y según el fin de su institución: luego el derecho de juzgar a sus ministros emana directamente del mismo que la fundó, y no viene de otra parte. Siendo pues el fuero eclesiástico, no una simple concesión a los individuos del clero, sino el derecho que la Iglesia tiene por su misma constitución divina, por la naturaleza de objetos y dentro de los límites de su institución para juzgarlos, no puede considerarse como un privilegio, pues para esto

${ }^{20}$ Donoso, Instituciones de derecho canónico americano, t. I, pp. 104-106. 
sería preciso suponerle como la excepción de una ley eclesiástica, que no existe, sino como una ley general. ${ }^{21}$

Si en los tratados de derecho canónico de mayor uso en la época resulta imposible hallar una posición compartida respecto a la naturaleza jurídica del fuero, en los manuales de práctica forense escritos y utilizados por letrados civiles se advierte de inmediato un claro consenso respecto al carácter privilegiado de las inmunidades clericales, muy a tono con el regalismo predominante desde el siglo xvirI. Que el fuero tuviera la naturaleza de privilegio significaba fundamentalmente que la inmunidad sólo era una concesión graciosa de los poderes civiles, quienes podían "limitarla y abolirla cuando y como les parezca”. ${ }^{22}$ Esto es, el fuero no era un derecho - natural o divino - que el clero pudiera afirmar como propio siempre y en todo lugar, sino una prerrogativa sujeta a la buena voluntad del soberano secular, a quien pertenecía de manera exclusiva el ejercicio del imperio y "la jurisdicción suprema, civil y criminal”. ${ }^{23}$ ¿Significaba esto que el fuero eclesiástico debía ser eliminado a la primera oportunidad? Para Manuel de la Peña y Peña, ministro de la Suprema Corte entre 1824 y 1850, y autor de uno de los manuales más consultados en el siglo XIX — sus voluminosas Lecciones de práctica forense mejicana (1836) - , la permanencia o desaparición de los privilegios jurisdiccionales del clero debía valorarse atendiendo al "bien común de la sociedad", pues todo privilegio era "odioso por sí mismo"

21 Munguía, Defensa eclesiástica, t. I, p. 6.

22 EsCRICHe, Diccionario razonado, pp. 355, 572.

23 Curia Filípica Mexicana, p. 535. 
y para la conservación de tribunales especiales se requerían motivos verdaderamente "urgentes". ${ }^{4}$ Según este jurista, era manifiesto que los "inconvenientes" de las inmunidades personales eran "ciertamente mayores que las ventajas" derivadas de su establecimiento, y por ello recomendaba explícitamente la pronta "abolición de los fueros especiales". ${ }^{25}$

Las razones que subyacían a esta dura recomendación podrían resumirse en dos argumentos. En primer lugar, Manuel de la Peña denunciaba la incompatibilidad de los fueros privilegiados con los principios igualitarios en que se asentaba el régimen republicano. En su opinión, "todas las leyes y reglas de la administración pública, y señaladamente las de la administración de justicia", debían "acomodarse a la forma de gobierno adoptada por la nación”. Si dicho sistema de gobierno estaba "cimentado sobre la base cardinal de la igualdad ante la ley", los eclesiásticos - en tanto ciudadanos de pleno derecho- no podían "eximirse de las bases fundamentales de la misma forma de gobierno". ${ }^{26}$ Este argumento igualitario fue invocado en todos los ataques al fuero eclesiástico por parte de los gobiernos y juristas liberales de las repúblicas hispanoamericanas, al punto que el papa Pío IX se vio obligado a censurarlo en su condena de la influyentísima obra del clérigo peruano Francisco de Paula Vigil, Defensa de la autoridad de los obispos y de los gobiernos contra las pretensiones de la curia romana, publicada por primera vez en Lima en $1848 .{ }^{27}$ A la par de este argumento, sin embargo, Manuel de la Peña también insistía en que los

${ }^{24}$ Peña, Lecciones de práctica forense, pp. 371-372, 432.

${ }^{25}$ PEÑA, Lecciones de práctica forense, p. 423.

${ }^{26}$ PEÑA, Lecciones de práctica forense, pp. 499-500.

27 Downs, The Concept of Clerical Immunity, pp. 38, 69-70. 
tribunales especiales eran indeseables por sus efectos nocivos en la marcha cotidiana del sistema judicial. Citando las Lecciones de política, según los principios del sistema popular representativo adoptado por las naciones americanas (1828), escritas por el jurista y “ciudadano americano” Luis Fernando Rivero, el ministro De la Peña ilustraba de esta manera los inconvenientes prácticos del régimen vigente:

[La] diversidad de fueros se opone sobremanera a la unidad del sistema en la administración, a la energía del gobierno, al buen orden y tranquilidad del Estado: porque presenta infinitos subterfugios, dilaciones y arbitrariedades ingeniosas a los litigantes temerarios, a los jueces lentos o poco delicados, a los ministros de justicia que quieran poner a logro el inmenso caudal de su cavilosa sagacidad, y viene a establecerse así un tal conflicto de autoridades que anula el imperio de la ley, y asegura la impunidad de los delitos. ${ }^{28}$

Según se advierte en esta cita, el fuero estaba íntimamente ligado a tres grandes problemas de la administración de justicia: en primer lugar, el desarreglo, lentitud e ineficiencia del sistema judicial; en segundo, el aumento visible de los delitos y de la impunidad de los mismos; y, por último, la escasa autoridad de un Estado débil que no era capaz de afirmar su soberanía frente a otras potestades. Durante las décadas previas al decreto del 23 de noviembre de 1855, fueron estos tres problemas $-\mathrm{y}$ no tanto el debate abstracto sobre la incompatibilidad entre la inmunidad personal y la igualdad republicana - los que más atención y energía demandaron por parte de jueces, gobernadores y sucesivos

${ }^{28}$ PEÑA, Lecciones de práctica forense, p. 392. 
encargados del Ministerio de Justicia. Tras analizar cada uno por separado podremos entender por qué la Curia Filípica Mexicana (1850) aseguraba que la extinción de los fueros no era "una producción nueva de un exaltado liberalismo, sino una idea antigua", que debía ser considerada de nuevo en atención a la "conveniencia pública del orden judicial". ${ }^{29}$

\section{EL ANHELO DE UNIFORMIDAD Y EFICIENCIA}

Como ha destacado la historiografía reciente, en el mundo colonial hispano la gestión del orden público era indisociable del ejercicio de la jurisdicción, es decir, del poder de resolver una controversia y establecer la equidad declarando el derecho aplicable al caso concreto. ${ }^{30}$ Una de las funciones primordiales del soberano era precisamente la de dispensar justicia, entendida como la restauración de la armonía social mediante el acomodo de intereses en conflicto y el castigo de transgresiones intolerables, atendiendo siempre a los imperativos de la circunstancia específica y, evidentemente, al complejo universo de normas aplicables, integrado por las leyes del reino, la costumbre establecida, las reglas del derecho común y los principios de la moralidad cristiana. La independencia de México no modificó en lo esencial este vínculo profundo entre la gestión del orden público y la jurisdicción, pues los primeros gobiernos republicanos insistieron, una y otra vez, en que la "buena administración

${ }^{29}$ Curia Filípica Mexicana, p. 18.

30 Véase Garriga, "Orden jurídico y poder político"; Agüero, "Las categorías básicas de la cultura jurisdiccional"; LirA, "La actividad jurisdiccional del virrey" y Moriconi, Política, piedad y jurisdicción, pp. 31-42. 
de justicia" era la "base de la sociedad". ${ }^{31}$ En 1831, por citar uno entre muchos ejemplos similares, el gobernador del Estado de México, Melchor Múzquiz, subrayaba de esta manera el papel crucial de la justicia como cimiento de la gobernabilidad:

De cuantos principios constitucionales existen, ningunos necesitan nunca más miramiento que los del poder judicial. Ésta es la parte más importante de la constitución de un Estado, como que de ella depende cuanto vale y cuanto tiene el ciudadano; ella es el origen y defensa del espíritu público, y el mantenedor de las reglas que constituyen la sociedad. En vano se proclamarán como elementos de la organización social, los derechos de libertad, seguridad y demás que forman las garantías públicas, si no se hacen efectivas por aplicaciones reales y positivas de tribunales justos e ilustrados, inaccesibles al crimen como a las pasiones. Ellos deben ser los depositarios de la libertad práctica de un pueblo, ante quienes el oprimido halle consuelo, y el poderoso un freno saludable a los excesos de su ambición. ${ }^{32}$

Precisamente por su importancia en el mantenimiento de "las reglas que constituyen la sociedad", la presencia de obstáculos a la pronta y eficaz administración de justicia era un motivo constante de preocupación para los gobiernos de todos los niveles. Muchos de estos obstáculos no eran sino reflejo de la pobreza de medios que aquejaba al Estado en su conjunto: el presupuesto nunca era suficiente para el sostenimiento digno de la judicatura y en la mayoría de los

31 Memoria en que el Gobierno del Estado Libre y Soberano de México (1828), p. 60.

32 Memoria en que el Gobierno del Estado Libre de México (1831), p. 65. 
estados escaseaban los letrados profesionales que pudieran desempeñarse como jueces o asesores de los mismos. Más allá de las carencias materiales, sin embargo, el mal funcionamiento del poder judicial parecía deberse, según explicaba el ministro de Justicia en su informe de 1835, a la

[...] falta de leyes nacionales que sistemen radicalmente de un modo sencillo, regular y digno de la filosofía del siglo y del carácter y costumbres del pueblo mexicano, la administración de justicia en lo civil y criminal, librando a los funcionarios del laberinto y confusión en que luchan con una multitud de fórmulas, requisitos y complicaciones, y con unas leyes y disposiciones incoherentes, heterogéneas y aún contradictorias. ${ }^{33}$

Esto es, la justicia se hallaba en total desarreglo porque faltaban códigos que facilitaran la racionalidad, uniformidad y eficiencia en el trabajo judicial.

$\mathrm{El}$ anhelo de salir del "laberinto tenebroso en que casi es imposible al juez y al ciudadano encontrar la norma segura de sus deberes" 34 fue un impulso decisivo no solamente para la labor codificadora - cuyos frutos se verían hasta la segunda mitad del siglo XIX - sino también para la abolición de los fueros privilegiados. Como explicaba Manuel de la Peña y Peña, la presencia de tribunales especiales era esencialmente incompatible con el "principio elemental de la uniformidad judicial”, pues "cada tribunal especial exige

33 "Memoria del Ministerio de Justicia y Negocios Eclesiásticos de la República Mexicana, 1835”, en Memorias de la Secretaría de Justicia, p. 127.

${ }_{34}$ Memoria en que el Gobierno del Estado Libre y Soberano de México (1828), p. 60. 
jueces especiales, especiales formas, especial modo de enjuiciar, especial práctica, especiales recursos [y] especial legislación" ${ }^{35}$ En los hechos, la sola invocación de una jurisdicción especial podía alargar notablemente la duración de un litigio: si un litigante necesitaba retrasar la discusión del fondo de un asunto, le bastaba con promover un juicio de competencia - entre la jurisdicción ordinaria y la especial - para obligar a una instancia superior a determinar primero cuál era el foro donde debía decidirse su causa. ${ }^{36}$ Podemos darnos una idea de los enormes costos derivados de esta y otras artimañas similares si consideramos los datos que recoge la memoria del gobierno de Jalisco de 1832: únicamente aquel año, para resolver 446 asuntos, el Tribunal Superior del estado había tenido que decidir previamente 3603 "providencias de trámite y substanciación”, sin contar "todos los pasos y trámites que antes [fue] necesario correr en los tribunales de primera instancia". ${ }^{37}$

En el caso particular del fuero eclesiástico, sus reglas especiales eran particularmente problemáticas en al menos dos aspectos. En primer lugar, la distribución geográfica de los tribunales eclesiásticos y su complejo sistema de apelaciones dificultaba en gran medida el seguimiento de los juicios para los demandantes y abogados que no residían en las capitales

35 PeÑA, Lecciones de práctica forense, p. 397.

36 La Curia Filípica ilustraba este problema con el siguiente ejemplo: "si se trata de un negocio que bajo algún aspecto pudiera considerarse mercantil, habría ocasión de promoverse una competencia entre un tribunal ordinario y el de comercio; mas si este segundo no existiera, no podría haber semejante competencia”. Curia Filípica Mexicana, p. 17.

37 "Memoria que el Excmo. Señor Gobernador del Estado de Jalisco leyó ante el Honorable Congreso al abrir sus sesiones ordinarias" (1832), en Jalisco. Testimonio de sus gobernantes, p. 152. 
episcopales. ${ }^{38} \mathrm{Al}$ mediar el siglo XIX, en efecto, la Iglesia mexicana se hallaba dividida en once grandes diócesis cuyo territorio no coincidía con el de los estados de la República (véase el mapa 1). Judicialmente hablando, esto significaba, por ejemplo, que un juicio entablado por un ciudadano de Hermosillo contra su párroco terminaría siendo litigado ante el Provisorato de Culiacán, a casi $600 \mathrm{~km}$ de distancia. ${ }^{39}$ En caso de resultar inconforme con la sentencia de primera instancia, el afectado debía interponer su recurso en la jurisdicción del arzobispo metropolitano, cuya sede estaba en la ciudad de México. De ser necesaria una tercera instancia, ésta correspondería “al obispo más cercano respecto del que comenzó la causa”, es decir, al de Durango. ${ }^{40}$ En una época caracterizada por la penuria económica, el bandolerismo y el completo abandono de los caminos, estas reglas significaban que muchos conflictos que involucraban al clero terminaban sin solución simplemente a causa de lo costoso que resultaba llevarlos a un tribunal.

El largo peregrinar geográfico de las causas judiciales era un tema en particular sensible para los gobiernos estatales. A este respecto, la Constitución de 1824 había dispuesto originalmente que las causas civiles y criminales debían ser “fenecidas” en el territorio de los estados "hasta su última

38 PEÑA, Lecciones de práctica forense, p. 498; Memoria del Ministerio de Justicia y Negocios Eclesiásticos de la República Mexicana (1832), p. 17.

39 Como explica Berenise Bravo, cuando los curas denunciados estaban adscritos a parroquias lejanas de la capital episcopal, el juicio comenzaba “ante el juez eclesiástico o el vicario foráneo de su jurisdicción, quienes remitían posteriormente la sumaria al provisorato para la sentencia”. Bravo, La gestión episcopal de Manuel Posada, p. 131.

40 Sobre el sistema de apelaciones en la jurisdicción eclesiástica, véase Curia Filípica Mexicana, pp. 34-35. 


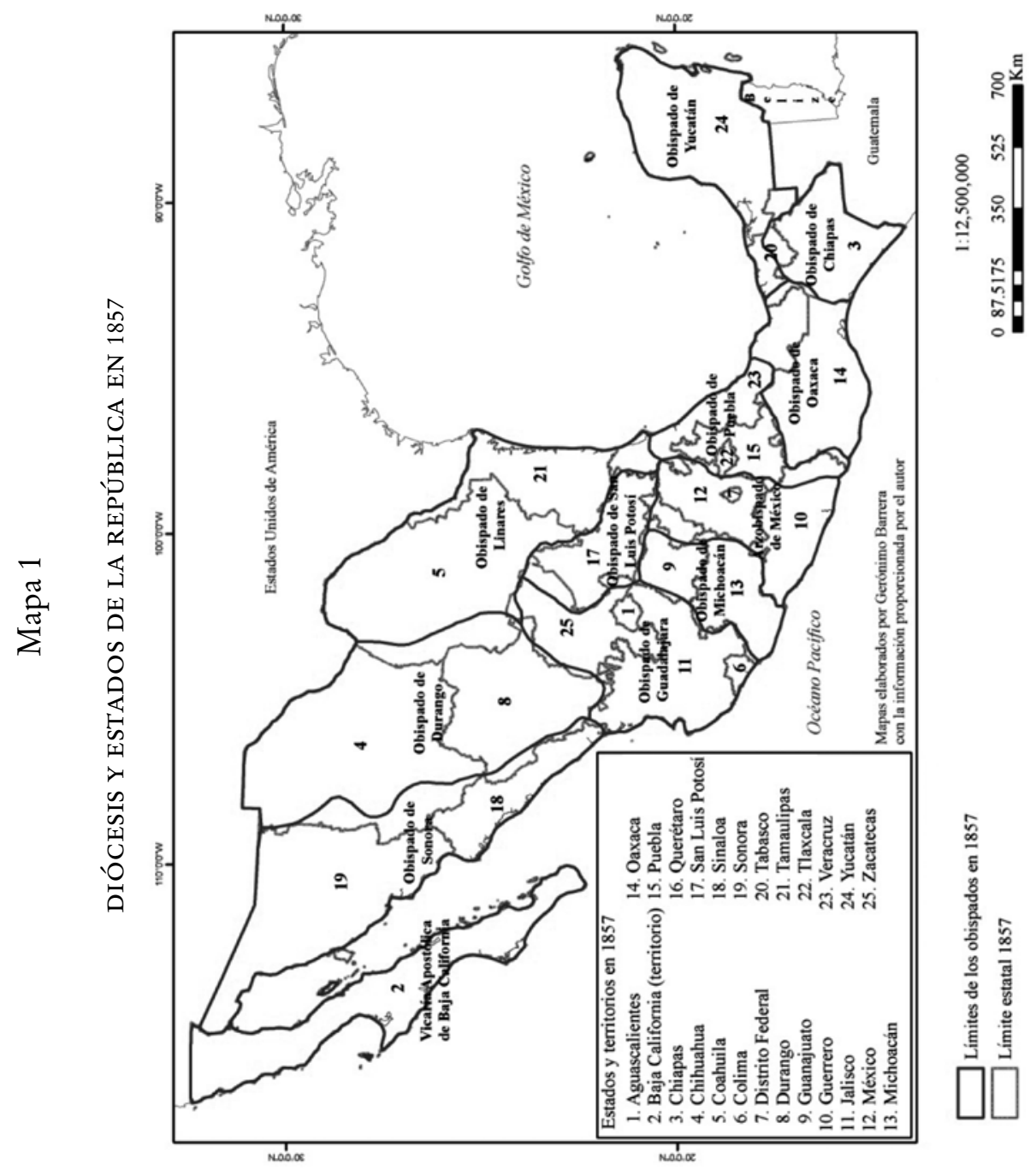


instancia y ejecución de la última sentencia” (art. 160). Esta regla desapareció con el sistema centralista (1836-1846), que introdujo el derecho a recurrir las sentencias de los tribunales superiores de los departamentos ante la Suprema Corte, pero se reimpuso con la restauración del federalismo en 1847. ${ }^{41}$ El celo de los estados por conservar los pleitos judiciales dentro de su territorio obedecía sin duda al deseo de preservar la soberanía estatal frente a los poderes centrales de la República, pero también respondía a los intereses económicos de las élites locales, que no estaban dispuestas a permitir que tribunales ajenos a su control - como los provisoratos y los juzgados de capellanías - resolvieran el destino de bienes y capitales ubicados en sus regiones. Así lo explicaba el gobernador mexiquense Lorenzo de Zavala en su memoria de 1828:

Ciudadanos del Estado libre y soberano de México, dependen en muchas cosas de un tribunal que está establecido fuera del mismo Estado. Ésta es una de las anomalías a que nos obliga lo reciente de nuestro establecimiento social. De aquí proviene, que la capital del Distrito tenga una preponderancia sobre el Estado, nacida además de sus riquezas y población, de que entre sus habitantes se distribuyen por el favoritismo, las gracias, destinos y riquezas, que no son pocas, de los fondos eclesiásticos con perjuicio de los habitantes del Estado. ${ }^{42}$

41 Cabe recordar, en este sentido, que el artículo 25 del Acta Constitutiva y de Reformas no facultaba a los tribunales federales para otorgar amparos contra resoluciones judiciales.

42 Memoria en que el Gobierno del Estado Libre y Soberano de México (1828), p. 64. 
Curiosamente, el segundo aspecto problemático del fuero eclesiástico era su incompatibilidad con algunos principios procesales que idealmente debían observarse en todo el país. Desde 1835 al menos, una pretensión constante y prioritaria de los gobiernos nacionales fue que "las leyes y reglas para la administración de justicia en lo civil y criminal” fueran "unas mismas en toda la Nación". ${ }^{43}$ Esta política no desapareció con la restauración del federalismo en 1847, pues la lógica del Acta Constitutiva y de Reformas era que el poder se distribuyese equitativamente entre todas las entidades que integraban la República, pero que el ejercicio del mismo - en particular en el ámbito judicial - se rigiera por principios universalmente aceptados y reconocidos por la ley suprema de la federación. Como explicaba Mariano Otero en su célebre "voto particular" presentado al Congreso constituyente en abril de 1847, la protección de las "garantías individuales" - "principios dictados por la razón” - era "el objeto primordial de las instituciones sociales", y en esa medida dicha tarea no podía quedar a merced de la "absoluta discreción de los estados”: la Constitución debía arreglarse de modo tal que "ninguno de los hombres que habiten en cualquiera parte del territorio de la República, sin distinción de nacionales y extranjeros, tengan que extrañar sobre este punto las mejores leyes de la tierra". ${ }^{44}$ El principal reto que este proyecto involucraba no era difícil de advertir: si los derechos constitucionales eran efectivamente los mismos para cualquier habitante de la República, ¿qué pasaría cuando los jueces eclesiásticos desconocieran tales derechos apelando a las reglas propias del derecho canónico?

43 PeÑa, Lecciones de práctica forense, p. 396.

44 Otero, "Voto particular" (1847), en Obras, t. I, pp. 363-364. 
Esta misma pregunta fue formulada al Ministerio de Justicia y Negocios Eclesiásticos en el verano de 1850, a raíz de un pequeño escándalo que fue ampliamente comentado por la prensa liberal. El 29 de junio de 1850, El Monitor Republicano denunció que Juan Pescador, un joven diácono que había sido expulsado del Colegio de San Gregorio por sus “malas costumbres”, había sido sorprendido oficiando una misa en la iglesia de Loreto, en la ciudad de México, cosa que pudo hacer gracias a que se había apoderado de las licencias ministeriales de un sacerdote fallecido durante la última epidemia de cólera. ${ }^{45}$ La conducta de Pescador era a todas luces delictiva y por lo tanto fue aprehendido a los pocos días por órdenes del vicario capitular del arzobispado de México. Acto seguido, y observando un protocolo frecuentemente utilizado en casos similares, el vicario comisionó al presbítero José María Aguirre para instruir el juicio sumario contra el detenido. ${ }^{46}$ Hasta ese momento el procedimiento no había tenido nada de extraordinario e incluso mostraba públicamente el deseo del gobierno arzobispal por castigar la conducta fraudulenta del diácono a la brevedad posible. El 10 de julio siguiente, sin embargo, El Monitor Republicano publicó un duro artículo criticando la decisión del vicario capitular, cuyo argumento central se resumía de esta manera:

Don Juan Pescador es mexicano y goza hasta hoy de los derechos de ciudadanía [...] La ley fundamental prohibió todo juicio por comisión lo mismo que toda ley retroactiva: esa

45 El Monitor Republicano (29 jun. 1850). El fuero protegía a todos aquellos que hubieran recibido órdenes menores o mayores en la Iglesia, no solamente a los sacerdotes.

${ }^{46}$ El Monitor Republicano (7 jul. 1850). 
prohibición es muy justa y racional y nadie puede fundadamente censurarla. Nombrar juez para formar la sumaria al respetable Sr. Dr. Aguirre es nada menos que establecer un juicio por comisión contra D. Juan Pescador. ${ }^{47}$

En términos estrictos, el argumento de El Monitor era impecable: el artículo 148 de la Constitución de 1824 prohibía de manera terminante todo "juicio por comisión”, entendido como aquel creado sólo "para conocer de cierta causa particular por tiempo determinado". En virtud de esta prohibición, todo ciudadano tenía derecho a ser juzgado por "leyes dadas y tribunales establecidos antes del acto por cual se le juzgue". ${ }^{48} \mathrm{El}$ gran problema en este caso, como lo advirtió inmediatamente el vicario capitular del arzobispado, es que en la jurisdicción eclesiástica casi todos los jueces lo eran por comisión, pues los obispos eran los "únicos jueces natos en las causas y negocios de su fuero". En efecto, a diferencia de los jueces civiles, los provisores y vicarios ejercían una jurisdicción delegada, que podía ser ampliada o restringida en cualquier momento: los obispos podían asumir siempre el conocimiento de asuntos pendientes y además podían remover a los provisores y vicarios "a su arbitrio y cuando les plazca, sin formación de causa ni otro requisito". Por si esto fuera poco, los prelados recibían con frecuencia comisiones jurisdiccionales por parte de las congregaciones vaticanas, de modo que ciertos juicios - como los de secularización de religiosos - fueran seguidos en México y no en Roma. ${ }^{49}$ En suma, el mandato

${ }^{47}$ El Monitor Republicano (10 jul. 1850).

48 PeÑa, Lecciones de práctica forense, p. 374.

49 AGN, Justicia, Eclesiástico, t. 166, ff. 493-494. 
constitucional de que los juicios fueran conducidos por tribunales previamente establecidos era inaplicable en el ámbito eclesiástico, pues las delegaciones de jurisdicción eran una práctica aceptada y consistente con el buen gobierno de la Iglesia.

La solución propuesta por el Ministerio de Justicia era muy práctica: a fin de evitar que los gobiernos diocesanos extendieran comisiones especiales para juzgar actos ocurridos antes de su establecimiento, bastaría con que los obispos eligieran tres o más “suplentes natos", quienes, con un nombramiento anticipado, cubrirían las ausencias del juez natural de manera regular y ordenada, como sucedía en los juzgados federales de distrito. ${ }^{50} \mathrm{El}$ vicario capitular, sin embargo, rechazó esta propuesta y la comparó con el absurdo intento de imponer el principio de división de poderes en la disciplina universal de la Iglesia. ${ }^{51}$ El caso de Juan Pescador no pasó a mayores, pero fue una clara señal de que el clero resistiría cualquier intento gubernamental de modificar sus reglas jurisdiccionales en aras de crear un sistema judicial uniforme. Para los redactores de El Monitor Republicano, el caso había sido un ejemplo más de la tendencia de las autoridades eclesiásticas a entrar "en una especie de pugna con las leyes humanas" y a frustrar "la pronta y recta administración de justicia”. Su mayor temor, en este sentido, era que las constantes irregularidades en la actuación de los jueces eclesiásticos producirían "efectos que se deben evitar y aún acaso hasta la impunidad" de malhechores como

50 AGN, Justicia, Eclesiástico, t. 166, f. 492.

51 AGN, Justicia, Eclesiástico, t. 166, ff. 494-495. 
el diácono Pescador. ${ }^{52}$ ¿Por qué era tan urgente asegurarse de que los delitos del clero fueran juzgados prontamente y con todo apego a la ley?

\section{EL PROBLEMA DE LA IMPUNIDAD CLERICAL}

Las primeras décadas de vida independiente fueron uno de los periodos de mayor criminalidad en la historia de México. Todas las fuentes posibles - desde la documentación oficial hasta la correspondencia privada, los relatos de viajeros, la literatura y las artes gráficas - coinciden en la imagen de un país hobbesiano, en el que las vidas, derechos y patrimonios de los ciudadanos nunca estaban a salvo de la violencia criminal. El notorio crecimiento de la delincuencia obedecía a múltiples causas, como la permanente crisis económica, la inestabilidad política y el desarraigo social de miles de jornaleros y veteranos de guerra, pero sin duda también estaba vinculado a un ambiente de impunidad generalizada. ${ }^{53}$ El propio ministro de Justicia lo reconocía abiertamente en su informe de 1830:

Dentro y fuera de poblado se ven desórdenes de toda especie. Los delincuentes se pasean impunes a pocos días de haber sido sorprendidos con la presa en las manos, y con la cuchilla también empapada muchas veces en sangre de la que vertió un inocente. Son conocidos por sus nombres, viven entre nosotros, andan por todas partes con osada frente, forman cuadrillas numerosas, y es tal el terror y miedo con que los vemos, que

${ }^{52}$ El Monitor Republicano (10 jul. 1850).

${ }^{53} \mathrm{Al}$ respecto, véase sobre todo Solares, Bandidos somos y en el camino andamos. 
no hay quien se atreva a acusarlos ni a deponer muchas veces en su contra por no sufrir la cruel venganza que debe esperarse de enemigos tan formidables. No hay asilo que nos ponga a cubierto de sus tiros, ni hay hora del día en que nos podamos sentir seguros. ${ }^{54}$

Este ambiente de impunidad era una de las principales causas del malestar público contra los gobiernos y la judicatura, pues la ciudadanía consideraba que los delincuentes permanecían libres por culpa de jueces venales, “plagados de ignorancia e inmoralidad”, de gobernantes que toleraban la corrupción judicial, y de legislaturas incapaces de adoptar "leyes aterradoras y coercitivas" para frenar el crimen. ${ }^{55}$ Es en este contexto de descrédito de las autoridades civiles que debe leerse el creciente interés de los gobiernos republicanos por restringir al máximo posible el fuero eclesiástico en materia criminal. A decir verdad, no existe la menor evidencia de que el clero católico fuera un grupo social más propenso al crimen que otros, y que por lo tanto requiriera de una vigilancia más rigurosa por parte del Estado. La obsesión gubernamental por evitar la impunidad clerical tenía que ver, más bien, con la ejemplaridad y el peso social de la conducta de los clérigos. En una nación que se definía como “exclusivamente católica”, el buen comportamiento del clero era un asunto de Estado porque la Iglesia seguía ejerciendo

54 "Memoria que leyó el Secretario de Estado y del Despacho Universal de Justicia y Negocios Eclesiásticos en la Cámara de Diputados" (1830), Memorias de la Secretaría de Justicia, p. 57.

55 "Memoria del Ministerio de Justicia y Negocios Eclesiásticos de la República Mexicana” (1835), Memorias de la Secretaría de Justicia, p. 127. Véase también SCARDAVILle, "Los procesos judiciales y la autoridad del Estado”. 
"una influencia general muy poderosa en la tranquilidad, paz y prosperidad de los individuos", según asentaba el informe del Ministerio de Justicia en $1828 .{ }^{56}$ Los editores de la versión mexicana de la Práctica forense criminal de José Marcos Gutiérrez (1830), una de las obras más citadas por los jueces y abogados de la época, también admitían que los delitos cometidos por los ministros de culto, aunque fueran poco frecuentes, provocaban más escándalo que "los de los seculares, y regularmente más de lo que merecen": "Cometido un delito grave por alguno de ellos, al punto se difunde en toda la ciudad y se extiende también en las provincias más distantes, agravándose siempre el hecho y sus circunstancias". ${ }^{57}$

Ciertamente, la inmunidad personal del clero no era sinónimo de impunidad: sólo significaba que los clérigos serían juzgados y castigados por sus pares y no por los jueces civiles. Sin embargo, en el ámbito criminal había dos poderosas razones por las que este sistema no era conveniente. En primer lugar, los jueces eclesiásticos podían imponer “censuras" espirituales - como la excomunión-y penas propiamente dichas, como la cárcel, el destierro y la confiscación de bienes, pero por ningún motivo podían dictar "penas de sangre y otras corporales de gravedad", lo que les impedía castigar ejemplarmente los peores delitos. ${ }^{58}$ Según

\footnotetext{
${ }^{56}$ Memoria que en cumplimiento del artículo 120 de la Constitución Federal de los Estados-Unidos Mexicanos, leyó el Secretario de Estado y del Despacho universal de Justicia y Negocios Eclesiásticos (1828), p. 6. 57 “Apéndice del editor", en J. M. GuTiÉrrez, Práctica forense criminal, pp. 14-15.

58 “Apéndice del editor", en J. M. Gutiérrez, Práctica forense criminal, p. 11; Rubial et al., La Iglesia en el México colonial, pp. 80-81.
} 
Manuel de la Peña, había eclesiásticos "tan criminosos e incorregibles" que para su enmienda eran "inútiles las penas canónicas y las penitencias saludables de la Iglesia". ${ }^{59}$ En segundo y más importante lugar, existía una percepción generalizada de que los jueces eclesiásticos tendían a mostrar un espíritu de "lenidad" al momento de castigar a los reos de su fuero, lo cual incrementaba el riesgo de que muchos crímenes escandalosos quedaran impunes (resulta imposible no advertir la similitud con el escándalo contemporáneo frente al encubrimiento de clérigos pederastas en diócesis de todo el mundo).

Fue por estas dos razones que, desde el último tercio del siglo XVIII, la corona española había introducido una serie de reglas especiales para el procesamiento de clérigos acusados de la comisión de delitos "atroces y gravísimos como los de lesa majestad, sedición, asesinato y otros semejantes". ${ }^{60} \mathrm{En}$ estos casos, el proceso debía formarse por "la justicia real en unión con la ordinaria eclesiástica, hasta poner la causa en estado de sentencia”. De encontrarse suficiente evidencia de la culpabilidad de un reo, el juez eclesiástico le dictaría primero la pena de degradación - es decir, la pérdida del estado clerical - e inmediatamente después lo entregaría al juez secular, para que éste ejecutara la pena corporal correspondiente. La corona pidió a los jueces eclesiásticos que mostraran "la mayor conformidad y buena armonía" con este mecanismo, pues su finalidad principal no era otra

\footnotetext{
${ }^{59}$ PeÑA, Lecciones de práctica forense, p. 562.

${ }^{60}$ Curia Filípica Mexicana, p. 543. La atrocidad o gravedad de un delito se determinaba en función del daño o perjuicio que éste hiciera a la sociedad; así, "cuanto mayor sea [el daño], otro tanto será más grave el delito". Romero, Prontuario alfabético, p. 73.
} 
que "el espíritu de justicia que exige la vindicta pública”. ${ }^{61}$ Como observa Nancy Farriss, esta reforma fue adoptada en el contexto de un asalto sin precedentes a los bienes y la presencia social de la Iglesia en el Imperio español, y en esa medida también pretendía dotar a la corona de los medios para frenar y sancionar cualquier conducta desleal de los clérigos, a quienes se consideraba cada vez más una amenaza potencial para la seguridad del Estado. ${ }^{62}$

Los peores miedos de la corona española se materializaron con la participación de decenas de sacerdotes en el movimiento insurgente que estalló en la Nueva España en septiembre de 1810. Una vez ejecutado el padre Miguel Hidalgo, y con el objeto de prevenir cualquier brote futuro de insurgencia clerical, el virrey Francisco Xavier Venegas decretó en junio de 1812 que todos los que "hicieren resistencia a las tropas del rey, de cualquier clase, estado o condición que fuesen", serían juzgados y ejecutados sumariamente por un consejo de guerra, sin darles otro privilegio que la oportunidad de confesarse y arrepentirse de sus crímenes. ${ }^{63}$ Lejos de lograr sus objetivos, esta medida radicalizó aún más a los clérigos insurgentes y reforzó la identidad de su movimiento como una defensa de la "verdadera religión" contra los “bárbaros” que, siguiendo el ejemplo de Napoleón, habían ultrajado el sacerdocio hasta la ignominia. La revolución liberal española de 1820 no puso fin al malestar clerical, pues el 26 de septiembre de aquel año las Cortes derogaron completamente el fuero eclesiástico en materia criminal: en

61 Curia Filípica Mexicana, p. 542.

62 FARris, La Corona y el clero en el México colonial, caps. VI y VII.

63 Ibarra, El clero de la Nueva España, pp. 106-107. 
adelante, cuando un clérigo cometiera "algún delito a que las leyes del reino impongan pena capital o corporis aflictiva", el juez ordinario secular podría proceder por sí solo a la sustanciación y determinación de la causa, "sin necesidad de auxilio ni cooperación alguna de la autoridad eclesiástica" ${ }^{64}$

Es bien sabido que el anticlericalismo de las Cortes liberales fue uno de los principales catalizadores del apoyo eclesiástico al Plan de Iguala y de la subsecuente consumación de la independencia de México. No es de sorprender, entonces, que el artículo 154 de la Constitución de 1824, con la intención de preservar los fueros privilegiados, dispusiera que los militares y eclesiásticos continuaran "sujetos a las autoridades a que lo están en la actualidad según las leyes vigentes". ${ }^{65}$ El problema con dicha redacción es que, bien a bien, nadie sabía cuáles eran dichas leyes vigentes: ¿ ‘se refería a la vieja tradición de la Iglesia, a las "jurisdicciones unidas” de la época borbónica o al reglamento de las Cortes de 1820 ? Con esta duda en mente, el 3 de septiembre de 1830 el cabildo catedral del arzobispado de México solicitó de manera formal al gobierno que adoptara las medidas necesarias para reinstaurar plenamente el fuero eclesiástico, el cual, "de hecho y no ciertamente por derecho alguno", había sido sometido a una "indebida degradación" desde que "se extendieron a los países llamados Indias la restricción de

\footnotetext{
64 “Apéndice del editor”, en J. M. Gutiérrez, Práctica forense criminal, pp. 3-4. Según la legislación española, las penas "corporis aflictivas" eran las de "extrañamiento del reino, presidio, galeras, bombas, arsenales, minas, mutilación, azotes y vergüenza pública”.

65 "Constitución Federal de los Estados Unidos Mexicanos" (1824), Carbonell Cruz Barney y Pérez Portilla (comps.), Constituciones históricas de México, p. 337.
} 
inmunidad, el desafuero y la unión de jurisdicciones”. El cabildo hizo un largo recuento de las reformas adoptadas por la corona española y destacó que las mismas no cumplían los requisitos formales de validez de las leyes y eran además fruto de "tiempos irreflexivos, crueles y bárbaros en que se creyó remediar al hombre con destrozarlo y acabarlo”. El afán de incrementar la seguridad en la República, insistió el cabildo, no era incompatible con la restauración del régimen disciplinar previo a las reformas borbónicas, bajo el cual los clérigos eran procesados sólo por los jueces de su fuero, sin importar el crimen que hubieran cometido. ${ }^{66}$

Con su acostumbrada moderación, el Ministerio de Justicia y Negocios Eclesiásticos sólo respondió que la solicitud del cabildo sería examinada "con detención por su gravedad para promover lo que convenga". ${ }^{67}$ Ausente dicho examen, cuatro años más tarde la Cámara de Diputados consultó a la Suprema Corte cuáles eran las leyes que ésta había considerado vigentes en los casos relacionados con la inmunidad eclesiástica. La Corte citó 11 causas que habían caído bajo su conocimiento (en su mayor parte homicidios y recursos de fuerza) y sólo concluyó que era indudable la invalidez del reglamento de las Cortes del 26 de septiembre de 1820, toda vez que "ni las cámaras, ni el Supremo Gobierno, ni los tribunales de la Federación, ni alguna otra autoridad han mencionado siquiera a aquel decreto". ${ }^{68}$ A juzgar por el procedimiento seguido tras la conspiración fallida del fraile Joaquín Arenas en 1827, la práctica vigente en el caso

\footnotetext{
66 AGN, Bienes Nacionales, leg. 609, exp. 12.

67 AGN, Justicia, Eclesiástico, t. 96, f. 107.

68 ACSCJN, GA-1834-1582, ff. 10-13.
} 
de delitos graves seguía siendo la intervención conjunta de las jurisdicciones civil y eclesiástica, aun cuando una ley federal de 1826 había eliminado todo fuero en los "crímenes relativos a la independencia nacional" ${ }^{69}$ La vigencia de esta práctica, sin embargo, no era una respuesta suficiente ni para la Iglesia - que seguía esperando la reinstauración del fuero en su plenitud - ni para los juristas, quienes regularmente se topaban con múltiples dudas y obstáculos en esta clase de asuntos.

En sus Lecciones de práctica forense, el ministro Manuel de la Peña volvió a insistir en la necesidad de superar esta penosa "diversidad de disposiciones dictadas en épocas y formas de gobierno diferentes" mediante una ley que arreglara "el orden de procederse en el conocimiento y castigo de los delitos públicos de los eclesiásticos" ${ }^{70}$ Esta ley era necesaria porque, en ausencia de reglas claras, los jueces eclesiásticos solían aprovecharse de las numerosas lagunas del derecho vigente para asegurar la impunidad de los reos de su fuero:

[Los jueces eclesiásticos] por lo regular han propendido a proteger la impunidad de los delincuentes bajo la capa de la inmunidad. No ha habido arbitrio de que no se hayan valido para lograrlo; ni el celo justo de los jueces seculares por el pronto escarmiento de los delitos, ni la eficacia de sus reclamos, ni la escrupulosidad de sus actuaciones, ni los recursos de fuerza interpuestos para contenerlos en sus demasías, ni las declaraciones consiguientes de los tribunales superiores, nada ha sido

69 “Apéndice del editor”, en J. M. Gutiérrez, Práctica forense criminal, p. 9. Véase también Iglesias y Morineau, "La causa contra el padre Arenas".

70 PeÑa, Lecciones de práctica forense, p. 576. 
bastante para que semejantes causas fueran terminadas pronta y debidamente. Persuadidos de que ganaban mucho con sólo ganar tiempo, han contraído principalmente sus esfuerzos a dilatar el pronto curso de las causas, dando así lugar a que se pierdan aquellos instantes en que el pueblo aún está penetrado de irritación y de dolor por la atrocidad del delito, y a que el deseo por la administración de justicia y el debido castigo del crimen cometido se destruya con el tiempo, prevaleciendo sólo los deseos naturales de la piedad hacia la persona del delincuente, y los del respeto a su carácter venerable. ${ }^{71}$

La permanencia de este problema a comienzos de la década de 1850 se ilustra muy bien con un caso que tuvo lugar durante el primer periodo de gobierno de Benito Juárez en Oaxaca. ${ }^{72}$ El 5 de octubre y el $1^{\circ}$ de noviembre de 1849 , el párroco Francisco Prado y su vicario Ildefonso Morga predicaron un par de sermones abiertamente subversivos en la cabecera del municipio de Ixtlán y en el vecino pueblo de Capulálpam, ambos ubicados en la sierra norte del estado. Las perturbaciones a la paz pública eran consideradas como un delito grave y por lo tanto la conducta de ambos presbíteros debía ser juzgada conjuntamente por la jurisdicción civil y la eclesiástica. El problema surgió cuando el provisor de la diócesis determinó que los sermones denunciados en realidad no constituían un delito "atroz o de lesa nación” y rechazó entonces la intromisión del juez civil de Ixtlán. En vista de la insistencia de este último, el 24 de mayo de 1850 el provisor decidió iniciar un juicio de competencia ante la Suprema Corte de Justicia, invocando un

71 PEÑA, Lecciones de práctica forense, pp. 550-551.

72 ACSCJN, J-1850-3723; AGN, Justicia, Eclesiástico, t. 166, ff. 530-538. 
artículo constitucional que era visiblemente inaplicable. ${ }^{73}$ En respuesta, el juez de Ixtlán promovió un recurso de fuerza contra el provisor ante el Tribunal Superior de Justicia del estado. Apenas fue informado de esta situación, el gobernador Juárez solicitó al Ministerio de Justicia que, en vista de las circunstancias, acelerara los trámites y pidiera a la Suprema Corte la resolución de este asunto a la brevedad posible, de modo que el tribunal superior pudiera sustanciar el recurso de fuerza y "resolver lo conveniente en un asunto de tan alta importancia". ${ }^{74}$

El 20 de noviembre de 1850, la Suprema Corte resolvió que el juicio de competencia era notoriamente improcedente y reenvió el expediente al Tribunal Superior de Oaxaca, el cual, a su vez, criticó al provisor de la diócesis por haber intentado "eximirse de la Jurisdicción del Estado" y por haber remitido las constancias del caso "sin preparación y debida sustanciación". ${ }^{75}$ Para ese momento, sin embargo, ya había pasado más de un año desde la comisión de los hechos y el juicio propiamente dicho aún no había comenzado. De nueva cuenta, el caso mostró la reticencia de los jueces eclesiásticos a permitir la intervención de la jurisdicción civil aun en los casos de delitos graves, e hizo patente la necesidad de una solución legislativa a este problema. Cuatro años más tarde, ya durante la dictadura del general Antonio López de Santa Anna, la Suprema Corte volvió

${ }^{73}$ El provisor citó la fracción IV del artículo 137 de la Constitución, la cual facultaba a la Suprema Corte para "dirimir las competencias que se susciten entre los tribunales de la federación, y entre éstos y los de los Estados, y las que se muevan entre los de un Estado y otro".

${ }^{74}$ AGN, Justicia, Eclesiástico, t. 166, f. 530.

75 ACSCJN, J-1850-3723, ff. 13-17. 
a ser consultada sobre la legislación aplicable en las "causas contra eclesiásticos por delitos atroces” (esta vez a raíz de la participación de un fraile dominico en el robo de una zapatería). La Corte respondió de nuevo que el decreto de las Cortes españolas de 1820 nunca había sido aplicado y confirmó que la única práctica vigente era la participación conjunta de las jurisdicciones civil y eclesiástica, añadiendo, sin embargo, que esta práctica no era "conforme con el espíritu de independencia que debe reinar entre ambas jurisdicciones" ni había podido "formar regla para fijar la conducta de los jueces en lo futuro". ${ }^{76}$

El decreto del 23 de noviembre de 1855 puso fin a estas dudas mediante el establecimiento de dos reglas nuevas acerca del modo de juzgar los crímenes cometidos por eclesiásticos. En primer lugar, el decreto eliminó la vieja distinción entre delitos atroces y leves, y la sustituyó por la de “comunes” en oposición a especiales. La Ley Juárez no definió qué se entendería por delito común, pero, por analogía con lo dispuesto para la jurisdicción militar en el artículo 42, es posible interpretar que se refería a todos aquellos delitos que no estuvieran directamente relacionados con la disciplina eclesiástica. La segunda regla consistió en disponer que, en el caso de los delitos comunes, el reo tendría derecho a escoger la jurisdicción donde se llevaría a cabo su juicio (se entiende que en el caso de los delitos especiales el juez natural sería siempre el eclesiástico). Juan Bautista Morales tenía razón cuando advirtió que, en materia penal, el decreto del 23 de noviembre había creado un privilegio que antes no existía. Y es que, en realidad, la

76 ACSCJN, J-1854-07-31-TS-TP-Con-Mx-4983, ff. 4-9. 
Ley Juárez no había pretendido introducir el principio de igualdad ante la ley en el ámbito criminal, sino, más bien, crear reglas claras que resolvieran las dudas jurisdiccionales existentes y facilitaran de ese modo el castigo de los clérigos delincuentes. Podría pensarse que la inédita concesión del derecho a escoger juez fue una medida pensada para tranquilizar al clero, pero los obispos la interpretaron como un intento de minar su autoridad disciplinaria. Lo que restaba era un enfrentamiento abierto entre las dos potestades y Juárez sabía por experiencia que la Iglesia opondría una resistencia formidable a su ley.

\section{LA DEBILIDAD Y EL DESPRESTIGIO \\ DE LA JURISDICCIÓN CIVIL}

La Ley Juárez no fue el primer intento mexicano de abolir los fueros privilegiados. Según Jesús Reyes Heroles, la primera supresión formal de los fueros se encuentra en el artículo 73 de la Constitución yucateca de 1841, cuyo proyecto fue elaborado por Manuel Crescencio Rejón, el jurista a quien se atribuye la creación del juicio de amparo. ${ }^{77} \mathrm{En}$ dicho proyecto, Rejón pedía suprimir las "funestas excepciones de la jurisdicción ordinaria” porque éstas habían sido la fuente de donde nacían "la indiferencia de los aforados por

\footnotetext{
77 Reyes Heroles, El liberalismo mexicano, t. III, p. 9. Es necesario notar, sin embargo, que esta Constitución fue adoptada en el contexto de una virtual separación de Yucatán de la República mexicana, pues en su preámbulo se hace referencia al "estado libre y soberano" de Yucatán, cuando las constituciones centralistas sólo reconocían a los departamentos como partes integrantes de la nación. La Constitución yucateca de 1841 estuvo en vigor hasta 1850.
} 
la conservación del orden civil, llevándolos con frecuencia hasta hacer alarde de desconocer las leyes fundamentales del Estado". El fuero, en su opinión, no era sino una monstruosa invención diseñada para "reunir a los hombres en cuerpos distinguidos, darles una grande preferencia, volverlos indiferentes o contrarios a la causa común, e interesarlos en el sostenimiento de una autoridad absoluta" ${ }^{78}$ En términos muy similares, Manuel de la Peña también había denunciado que la "mezcla y confusión" de jurisdicciones había dado lugar a "no pocas ni leves disputas" entre la potestad civil y la eclesiástica, pues la "potestad privilegiada" solía desconocer "el origen de que le viene el privilegio; sólo tiene presente su uso y ejercicio; y al tratar de defenderlo, lo atribuye a facultad propia, y a un deber que no puede negársele, ni siquiera restringírsele de algún modo". ${ }^{79}$ ¿A qué clase de disputas hacían referencia ambos juristas? ¿Era cierto que la Iglesia, en uso y defensa del fuero, había llegado al extremo de desconocer la autoridad civil?

Aunque todavía nos falta mucho por descubrir en los archivos episcopales y estatales, la historiografía disponible confirma que la vieja disputa entre el clero y las autoridades civiles por afirmar su respectiva "superioridad" en la vida de las comunidades arreció notablemente durante la primera mitad del siglo xIX. ${ }^{80}$ Uno de los principales frentes de esta disputa fue el ámbito judicial, pues hubo ocasiones en que los jueces eclesiásticos afirmaron su jurisdicción y superioridad frente a sus pares civiles de manera frontal e

\footnotetext{
78 Citado en Reyes Heroles, El liberalismo mexicano, t. III, pp. 9-10.

79 PeÑa, Lecciones de práctica forense, p. 483.

${ }^{80}$ Bravo, La gestión episcopal de Manuel Posada, p. 139. Véase también ORNELAS, "La dimensión parroquial de las tensiones Iglesia-Estado".
} 
incluso arrogante, olvidándose de juicios de competencia, excepciones procesales y demás estrategias dilatorias que al menos les permitían aparentar cierta deferencia ante la autoridad secular. Estos choques abiertos merecen atención especial porque la debilidad que exhibían los gobiernos y jueces de la República frente a los desafíos de la "potestad privilegiada” contribuyó mucho al (ya de por sí notable) desprestigio social de la jurisdicción civil. Como ilustran los siguientes dos casos ocurridos en Jalisco y Oaxaca durante la década de 1830, la supresión del fuero eclesiástico era una medida necesaria para afirmar la soberanía del Estado y poner un alto a la constante humillación pública de sus funcionarios.

El primer caso comenzó con un litigio aparentemente trivial: el 26 de junio de 1830, el ciudadano José Antonio Monroy interpuso una demanda contra la curia eclesiástica de Guadalajara ante el juzgado $5^{\circ}$ de la capital del estado, en la que exigía la subasta pública de las tierras de una cofradía local. Durante varios años Monroy había trabajado dichas tierras como arrendatario, pero su contrato había expirado y éstas ya habían sido vendidas a otra persona. La pretensión de Monroy era que esta última venta fuera anulada y que las tierras fueran enajenadas de nuevo mediante subasta, de modo que él pudiera adquirirlas. ${ }^{81}$ En otras palabras, el problema de origen era una disputa ordinaria entre dos ciudadanos por un terreno: una disputa cuya resolución debía corresponder a la jurisdicción civil. El litigio se complicaba, sin embargo, porque las tierras pertenecían a una cofradía y esto abría las puertas a la intervención de la

${ }^{81}$ AGN, Justicia, Eclesiástico, t. 95, ff. 106-108. 
jurisdicción eclesiástica. De hecho, Monroy había demandado directamente a la curia y el principio general era que la jurisdicción seguía el fuero del reo. El alcalde Magdaleno Salcedo, titular del juzgado $5^{\circ}$, decidió no obstante aceptar la demanda porque la Ley 124 del estado de Jalisco disponía que esta clase de litigios fueran sujetos primero a un proceso de conciliación, de modo que las partes pudieran ahorrarse un costoso y prolongado juicio de varias instancias. Según esta ley, dicho proceso de conciliación debía ser conducido sólo por los alcaldes constitucionales.

Una vez asumida su jurisdicción, el alcalde Salcedo citó a comparecer al defensor de obras pías del obispado, a fin de que contestara la demanda de Monroy y declarase su posición al respecto. Al llegarle noticia de este emplazamiento, el gobernador de la mitra de Guadalajara, José Miguel Gordoa, prohibió al defensor de obras pías que compareciera en el juzgado civil, y de inmediato envió una nota al alcalde cuestionando su decisión de admitir una demanda que era "tan propia y exclusivamente del conocimiento de este Gobierno Eclesiástico". Salcedo respondió a la nota con particular atrevimiento, pues primero hizo notar la extrañeza de que "el mismo demandado sea el juez que decida la demanda, cosa que no se encuentra autorizada por ninguna ley por bárbara que sea”, y varios días después emplazó al propio gobernador de la mitra bajo la advertencia de que, si se negaba a comparecer, le impondría una multa de "cincuenta pesos de irremisible exacción, sin perjuicio de las demás providencias que en el caso crea deban tomarse en Justicia". ${ }^{2}$ Para ese momento Gordoa ya había consultado la opinión

${ }^{82}$ AGN, Justicia, Eclesiástico, t. 95, ff. 106, 108. 
jurídica del promotor fiscal del obispado y éste había emitido un dictamen opuesto a las intenciones del alcalde:

La autoridad Eclesiástica no puede estar sujeta a la Civil, Jesucristo la estableció independiente, los cánones y leyes tienen ya demarcado el orden con que los que gobiernan la Iglesia pueden ser demandados, y no siendo el orden prescrito el de la conciliación ante el Alcalde, y estando vigentes todas las leyes protectoras de la inmunidad eclesiástica por el citado artículo de la Constitución Federal, se ha de servir V.S. manifestarlo así en contestación al citado Alcalde quinto, previniéndole que por el decoro de la autoridad que V.S. ejerce, si continuase en ser ésta amagada con citaciones ilegales, o conminaciones y palabras que la ultrajen, o cualquiera otra providencia atentatoria, el Gobierno de la Diócesis se hará respetar y sostendrá su decoro con las armas espirituales que tiene todo Católico. ${ }^{83}$

Lo previsible en este caso hubiera sido que la disputa entre el alcalde y el gobernador de la mitra se resolviera mediante un juicio de competencia o un recurso de fuerza. El 6 de julio, sin embargo, el alcalde decidió cumplir su amenaza: primero envió a un mozo a las oficinas del gobierno eclesiástico a cobrar la multa de 50 pesos y después mandó llamar a 20 soldados para que procedieran al arresto del presbítero Gordoa. Apenas se enteró de esta orden, el gobernador eclesiástico redactó un decreto de excomunión contra el alcalde y otro más en que declaraba "en entredicho" a la ciudad de Guadalajara, lo cual significaba que muy pronto se suspendería el culto público en la capital de

${ }^{83}$ AGN, Justicia, Eclesiástico, t. 95, f. 108. 
la tercera diócesis más grande del país. ${ }^{84} \mathrm{El}$ escándalo era mayúsculo y la noticia llegó “con la velocidad del rayo” a las principales ciudades de la República, dando lugar, a su vez, a varias manifestaciones de solidaridad clerical con la diócesis de Guadalajara. ${ }^{85}$ El peligroso curso que estaban siguiendo los acontecimientos pudo haber derivado en un levantamiento de no haber mediado la prudencia del comandante de la ciudad, quien se negó a colaborar en el arresto de Gordoa. El gobernador y el Tribunal Superior del estado se mantuvieron a la expectativa, pero el Ministerio de Justicia decidió frenar la disputa de inmediato.

El 17 de julio de 1830, el ministro de Justicia, José Ignacio Espinosa, solicitó al gobernador del estado de Jalisco que tomara "prontas y acertadas medidas" para poner fin a las desavenencias entre la mitra de Guadalajara y el alcalde Salcedo, sin excluir "la corrección y condigno castigo" a este último. El ministro reconoció que la legislación estatal había previsto que los eclesiásticos acudieran a la conciliación en los juicios relativos a sus "negocios privados", pero señaló que éste era un beneficio que no debía ser impuesto por la fuerza a las autoridades eclesiásticas, ignorando el debido "miramiento a su alto carácter" ${ }^{86}$ Desde el punto de vista del gobierno federal, "errores" como el de Salcedo sólo servían para provocar escándalos innecesarios y minar aún más el prestigio de la República, cuyos habitantes veían "con asombro en pugna a dos autoridades que deben

\footnotetext{
84 AGN, Justicia, Eclesiástico, t. 95, ff. 104-105, 108-110.

85 AGN, Justicia, Eclesiástico, t. 95, ff. 101-103.

86 AGN, Justicia, Eclesiástico, t. 95, f. 103.
} 
enlazarse". En esa medida, era necesario enviar el mensaje correcto a todos los funcionarios del Estado:

[Es necesario hacer] entender que el único modo de que cada funcionario desempeñe sus atribuciones es guardando la consideración debida a los otros, para que estos no le falten a la suya, por ningún pretexto, y que todos rijan a los Pueblos con su buena administración respectiva y sobre todo con el ejemplo, porque el desacato de una autoridad a otra, a las dos las deprime en el concepto del Pueblo, que muy fácilmente se acomoda a tratarlas con menosprecio. ${ }^{87}$

La intervención del ministerio cortó de tajo el escándalo y previno un desenlace trágico, pero tuvo un alto costo para las autoridades civiles de Jalisco en la medida en que las mostró débiles e impotentes frente a los arrebatos del gobierno diocesano. Una historia parecida tuvo lugar en Oaxaca cuatro años más tarde, teniendo esta vez como trasfondo el fracaso estrepitoso de la "reforma" eclesiástica promovida por el vicepresidente Valentín Gómez Farías a nivel federal. El principal protagonista de esta historia fue nada menos que Benito Juárez, quien se había recibido de abogado en enero de 1834 y apenas estaba comenzando a ejercer la profesión. El único testimonio que tenemos de esta historia se encuentra en las memorias póstumas del benemérito y hasta la fecha no ha sido corroborado por otras fuentes contemporáneas a los hechos. ${ }^{88} \mathrm{Si}$ bien esto podría llevarnos a cuestionar su veracidad, vale la pena incluirlo en este trabajo porque ilustra muy bien la visión que tenía el propio

${ }^{87}$ AGN, Justicia, Eclesiástico, t. 95, f. 103.

${ }^{88}$ Véase TAmayo, Benito Juárez, t. 1, cap. IV. 
Juárez de la indocilidad del clero y de la corrupción a la que había llegado con tal de preservar sus privilegios. Al igual que el caso de Jalisco, esta historia revela a una Iglesia poco obediente de la ley y muy capaz de someter públicamente a las autoridades de la República.

Según se desprende de este relato autobiográfico, a principios de 1834, el joven abogado Benito Juárez fue contratado por varios vecinos de San Agustín Loxicha (un pueblo indígena ubicado en la sierra sur del estado de Oaxaca) para que interpusiera una demanda contra su párroco ante el Provisorato de la diócesis. El origen del pleito era un problema que se repetía con demasiada frecuencia en todo el país: el párroco les cobraba obvenciones y servicios personales que no estaban previstos en los aranceles vigentes. Juárez no tardó en llevar sus quejas al tribunal y, en vista de la documentación presentada, el provisor "dio orden al cura para que se presentara a contestar los cargos que se le hacían, previniéndosele que no volviera a la parroquia hasta que no terminase el juicio que contra él se promovía". ${ }^{89}$ Por lo visto, la respuesta favorable del provisor se debía no sólo a los buenos oficios del abogado, sino al hecho de que Juárez también era diputado de la legislatura local. Los problemas comenzaron cuando la administración liberal de Gómez Farías fue depuesta por el presidente Santa Anna en abril de 1834. Desde aquel momento, apunta Juárez, "el partido clérico militar se lanzó descaradamente a sostener a mano armada y por medio de los motines, sus fueros, sus abusos y todas sus pretensiones antisociales". ${ }^{90}$

${ }^{89}$ JuÁrez, “Apuntes para mis hijos”, en Antología, p. 19.
90 JuÁrez, “Apuntes para mis hijos”, en Antología, p. 17. 
Al caer Gómez Farías cayeron también el gobierno y la legislatura del estado de Oaxaca. El exdiputado Juárez fue confinado en la ciudad de Tehuacán en represalia por su colaboración con el régimen depuesto, pero a las pocas semanas logró salir y consiguió trabajo como profesor sustituto de derecho canónico en el Instituto de Ciencias y Artes de la capital del estado. Aunque las cosas parecían volver a la normalidad, a fines de 1834 Juárez tuvo noticia de que sus clientes de San Agustín Loxicha habían sido apresados por orden del prefecto y del juez civil de la localidad. Juárez pidió licencia y marchó de inmediato hacia el pueblo de Miahuatlán, donde estaban recluidos sus clientes, con el fin de hablar con ellos y exigir su libertad. El juez de Miahuatlán le permitió visitar a los presos, pero se negó a darle información sobre el estado de la causa porque ésta era "reservada”. Juárez le hizo notar que el término para dictar el auto de formal prisión ya había transcurrido y le pidió que asentara su respuesta por escrito, de modo que pudiera comenzar los trámites necesarios para solicitar la libertad de sus clientes ante una instancia superior. Molesto y contrariado, el juez exigió a Juárez el poder formal que le habían dado los reos para litigar en su nombre, a lo que éste respondió que "siendo abogado conocido y hablando en defensa de reos pobres" no necesitaba de ningún poder formal en este asunto. En vista de ello, el juez le previno que se abstuviera de hablar y le pidió que volviera más tarde para rendir su declaración preparatoria en la causa que le abriría para juzgarlo como vago. ${ }^{91}$ Juárez optó por faltar a la incómoda cita y salió huyendo a la capital. ¿Qué había sucedido?

${ }^{91}$ JuÁrez, “Apuntes para mis hijos”, en Antología, pp. 19-20. 
La explicación que Juárez encontró para estos extraños acontecimientos arrancaba en el Provisorato de la diócesis: apenas había caído Gómez Farías, el provisor decidió revocar su decisión original en el asunto de San Agustín Loxicha y permitió que el cura acusado volviera a su parroquia, sin conceder siquiera audiencia a los quejosos. En cuanto llegó al pueblo, el cura recuperó su poder y logró convencer al juez y al prefecto de que detuvieran a los vecinos que lo habían denunciado. Pero las intrigas clericales no terminaron ahí. Una vez en la ciudad de Oaxaca, Juárez acusó al juez de Miahuatlán ante el Tribunal Superior del estado, donde "estaba también representado el clero", y previsiblemente no obtuvo respuesta ni amparo alguno. Insatisfecho con esta victoria judicial e "implacable" en su deseo de venganza contra los quejosos y su abogado, el cura hizo firmar entonces al juez de Miahuatlán un exhorto para que las autoridades de la capital aprehendieran a Juárez y lo remitieran a dicho pueblo de inmediato, bajo la absurda acusación de que estaba "sublevando" a los vecinos de San Agustín (cuando jamás había pisado dicho lugar). Juárez fue detenido por nueve días y logró salir de prisión bajo fianza, pero sin haber logrado que el Tribunal Superior confirmara su inocencia. Está claro que jamás se dio curso a las quejas que interpuso contra los jueces que atropellaron sus derechos.

Reflexionando sobre esta difícil experiencia varias décadas después de los hechos, Juárez apuntó que el caso de San Agustín Loxicha le enseñó que en el México de carne y hueso las "puertas de la justicia" estaban cerradas "para aquellos infelices que gemían en la prisión, sin haber cometido ningún delito, y sólo por haberse quejado contra las 
vejaciones de un cura". ${ }^{92}$ ¿Y por qué estaban cerradas? Porque el clero, peligrosamente fortalecido gracias a sus bienes y privilegios, manipulaba a las autoridades civiles a su antojo y las utilizaba como una mera herramienta de sus "intereses bastardos”. ${ }^{93}$ Es muy probable que al redactar estos apuntes en el contexto de la ruptura total entre la Iglesia y el Estado, Juárez le hubiera atribuido a esta experiencia un significado que no tuvo originalmente - como gobernador, de hecho, Juárez no fue un quijotesco defensor de los pueblos contra sus curas abusivos, sino más bien un político pragmático que mantuvo una buena relación con el obispo de Oaxaca e incluso adoptó medidas para asegurar el pago oportuno de las obvenciones parroquiales - ${ }^{94}$ Lo importante, en todo caso, es que Juárez utilizó esta historia como una explicación íntima de los antecedentes y razones de su polémico decreto del 23 de noviembre de 1855. A la luz de la memoria, la abolición de los fueros era el primer y fundamental paso en la construcción de una nación de verdad soberana, es decir, una nación cuyos gobernantes y representantes no fueran simples marionetas de las "clases privilegiadas":

Estos golpes que sufrí y que veía sufrir casi diariamente a todos los desvalidos que se quejaban contra las arbitrariedades de las clases privilegiadas en consorcio con la autoridad civil, me demostraron de bulto que la sociedad jamás sería feliz con la existencia de aquéllas y de su alianza con los poderes públicos y me afirmaron en mi propósito de trabajar constantemente

92 JuÁrez, “Apuntes para mis hijos”, en Antología, p. 21.

93 JuÁrez, “Apuntes para mis hijos”, en Antología, p. 19.

94 Hamnetт, Juárez, pp. 93-94. 
para destruir el poder funesto de las clases privilegiadas. Así lo hice en la parte que pude y así lo haría el Partido Liberal pero por desgracia de la humanidad el remedio que entonces se procuraba aplicar no curaba el mal de raíz, pues aunque repetidas veces se lograba derrocar la administración retrógrada reemplazándola con otra liberal, el cambio era sólo de personas y quedaban subsistentes en las leyes y en las constituciones los fueros eclesiástico y militar, la intolerancia religiosa, la religión de Estado y la posesión en que estaba el clero de cuantiosos bienes de que abusaba fomentando los motines para cimentar su funesto poderío. ${ }^{95}$

\section{CONCLUSIÓN: DE LA LEY JUÁREZ}

A LA LEY DE LIBERTAD DE CULTOS

La Ley Juárez fue la desembocadura de problemas y debates relacionados con la gestión judicial del orden público que habían tensado la relación Iglesia-Estado desde tiempos coloniales. Aunque la identificación entre la supresión de los fueros y el principio de igualdad ante la ley facilitó la legitimación pública de esta reforma, su principal objetivo era mejorar y fortalecer la administración de justicia, y en esa medida contribuir a la gobernabilidad del país. La Ley Juárez, en efecto, pretendía extirpar los principales obstáculos a la resolución judicial pronta, eficiente y uniforme de los conflictos sociales, los cuales habían aumentado en número y gravedad a lo largo de la primera mitad del siglo xix. Al remover estos obstáculos e imponer un solo fuero en la nación, la Ley Juárez también buscaba afirmar la supremacía efectiva del Estado en la vida pública, eliminando

95 JuÁrez, “Apuntes para mis hijos”, en Antología, p. 22. 
definitivamente los choques jurisdiccionales que tanto habían mermado la autoridad y el prestigio de los poderes civiles. Siguiendo la tesis de Edmundo O'Gorman sobre el sentido estatista de la revolución de Ayutla, podríamos decir que la abolición de los fueros privilegiados respondía, más que a un impulso democrático e igualitario, a la búsqueda de un "poder firme y enérgico" que mantuviera la paz e hiciera posible la reforma de la sociedad. ${ }^{96}$

A diferencia de lo que había sucedido con la reforma de Gómez Farías en 1833-1834, la férrea oposición clerical a la Ley Juárez sólo sirvió para unificar al Partido Liberal en torno a un enemigo común y para confirmar la necesidad de un cambio drástico en las relaciones Iglesia-Estado. Con esta meta en el horizonte, los diputados del Congreso constituyente de 1856-1857 elevaron la supresión de los fueros a rango constitucional y descartaron el único y novedoso privilegio que Juárez había concedido al clero en su decreto de 1855. De acuerdo con el artículo 13 de la Constitución de 1857, nadie podría ser juzgado por leyes privativas ni por tribunales especiales; ninguna persona o corporación podría tener fueros que no estuvieran claramente fijados por la ley, y sólo subsistiría el fuero de guerra para los delitos y faltas que tuvieran una "estricta conexión" con la disciplina militar. En adelante, las causas civiles y criminales de los eclesiásticos serían juzgadas sin excepción alguna en los tribunales ordinarios, los cuales se regirían idealmente por los principios procesales consagrados en el capítulo de "derechos del hombre" de la Constitución.

96 O’Gorman, “Precedentes y sentido de la revolución de Ayutla”, en Historiología, pp. 110-111. 
El llamado de los obispos a no jurar la Constitución de 1857 y el autogolpe de Estado encabezado por el presidente Comonfort a fines de ese mismo año llevaron al estallido de una sangrienta guerra civil que profundizó aún más la ruptura entre la Iglesia y el gobierno liberal. Ya como presidente constitucional, el 7 de julio de 1859 Benito Juárez decretó "la más perfecta independencia entre los negocios del Estado y los puramente eclesiásticos", con lo que dio paso a una serie de medidas que prácticamente expulsaron a los tribunales de la Iglesia de la vida social y económica del país: mientras que la nacionalización de bienes eclesiásticos confirmó la exclusiva jurisdicción del Estado en toda controversia relacionada con las propiedades o capitales del clero, las leyes del matrimonio civil, secularización de cementerios y registro público del estado civil de las personas ratificaron el monopolio estatal del derecho civil, familiar y administrativo. El golpe definitivo a la jurisdicción eclesiástica llegó con la Ley de libertad de cultos del 4 de diciembre de 1860, cuyo artículo $7^{\circ}$ prohibió a la Iglesia ejecutar "actos peculiares de la potestad pública”. Como explica Andrés Lira, esta prohibición significaba que sólo los tribunales del Estado podrían resolver controversias con el respaldo de la "coacción física legítima”, y que la jurisdicción eclesiástica quedaría confinada al ámbito de la conciencia. ${ }^{97}$

La supresión de los fueros privilegiados fue una de gestas centrales de la reforma liberal. Si evaluáramos su legado sólo en términos de la igualdad ante la ley, tendríamos que concluir que éste fue más bien parco: el Constituyente de 1856-1857 rechazó incluir expresamente el principio de que

97 Lira, “Jurisdicción eclesiástica y potestad pública”. 
"todos los habitantes de la república, sin distinción de clases ni de origen, tienen iguales derechos", ${ }^{98}$ y por ello la legislación posterior tampoco adoptó medidas eficaces para que los tribunales fueran imparciales frente a las enormes desigualdades socioeconómicas y étnicas que caracterizaban a la sociedad mexicana del siglo xix. No es de sorprender, en ese sentido, que en la administración de justicia realmente existente pesaran más el racismo y los prejuicios de clase que la estricta observancia de la ley. ${ }^{99}$ Sin embargo, la supresión de los fueros sí tuvo un legado formidable si lo juzgamos en términos de la consolidación del Estado: el monopolio estatal de la creación, aplicación e interpretación del derecho, logrado a expensas de la jurisdicción eclesiástica, fue el punto de partida fundamental en la construcción del orden jurídico mexicano que conocemos hoy en día. Aunque se trata de una hipótesis poco explorada por la historiografía, creo que la pacificación social, la centralización política y la recuperación económica que distinguieron a la época porfiriana deben mucho a la presencia del sistema judicial creado a partir de la Ley de Administración de Justicia de 1855.

\section{SIGLAS Y REFERENCIAS}

AGN Archivo General de la Nación, México.

ACSCJN Archivo Central de la Suprema Corte de Justicia de la Nación, México.

98 Reyes Heroles, El liberalismo mexicano, t. III, pp. 56-58.

$99 \mathrm{Al}$ respecto, véase sobre todo SPECKMAN, Crimen y castigo. 
AgüEro, Alejandro

"Las categorías básicas de la cultura jurisdiccional", en LoRENTE (coord.), 2007, pp. 19-58.

ArNold, Linda

Política y justicia. La Suprema Corte mexicana (1824-1855), México, Universidad Nacional Autónoma de México, 1996.

BARrios, Feliciano (coord.)

El gobierno de un mundo. Virreinatos y Audiencias en la América Hispánica, Cuenca, Ediciones de la Universidad de Castilla-La Mancha, 2004.

Bravo Rubio, Berenise

La gestión episcopal de Manuel Posada y Garduño. República católica y arzobispado de México, 1840-1846, México, Porrúa, 2013.

Bulnes, Francisco

Juárez y las revoluciones de Ayutla y de Reforma, México, Instituto de Investigaciones Dr. José María Luis Mora, 2011.

Carbonell, Miguel, Óscar Cruz Barney y Karla Pérez Portilla (comps.)

Constituciones históricas de México, México, Porrúa, Universidad Nacional Autónoma de México, 2004.

Casas, Juan Carlos y Pablo Mijangos (coords.)

Por una Iglesia libre en un mundo liberal. La obra y los tiempos de Clemente de Jesús Munguía, primer arzobispo de Michoacán (1810-1868), México, Universidad Pontificia de México, El Colegio de Michoacán, 2014.

Connaughton, Brian (coord.)

Poder y legitimidad en México en el siglo XIX. Instituciones y cultura política, México, Universidad Autónoma Metropolitana, Miguel Ángel Porrúa, 2003. 


\section{Curia Filípica Mexicana}

Curia Filípica Mexicana. Obra completa de práctica forense en la que se trata de los procedimientos de todos los juicios, ya ordinarios, ya extraordinarios y sumarios, $y$ de todos los tribunales existentes en la República, tanto comunes como privativos y privilegiados, México, Imprenta de Mariano Galván Rivera, 1850.

Del Re, Niccolò

La Curia Romana. Lineamenti Storico-Giuridici, Roma, Libreria Editrice Vaticana, 1998.

Diccionario

Diccionario de derecho canónico arreglado a la jurisprudencia española antigua y moderna, París, Librería de Rosa y Bouret, 1854.

Documentos

Documentos básicos de la Reforma, 1854-1875, México, Partido Revolucionario Institucional, 1982, 4 tomos.

Donoso, Justo

Instituciones de derecho canónico americano, para el uso de los Colegios de las Repúblicas de la América española, París, Librería de Rosa, Bouret y Cía., 1852, t. III.

Instituciones de derecho canónico americano, para el uso de los colegios de las repúblicas de la América española, Valparaíso, Imprenta y Librería del Mercurio, 1848, t. I.

Downs, John Emmanuel

The Concept of Clerical Immunity, Washington, The Catholic University of America Press, 1941.

Elsacrosanto

El sacrosanto y ecuménico Concilio de Trento, traducción al castellano de Ignacio López de Ayala, Barcelona, Imprenta de Sierra y Martí, 1828. 
EsCRICHE, Joaquín

Diccionario razonado de legislación civil, penal, comercial y forense, México, Imprenta de Galván a cargo de Mariano Arévalo, 1837.

FARriss, Nancy M.

La Corona y el clero en el México colonial, 1579-1821. La crisis del privilegio eclesiástico, México, Fondo de Cultura Económica, 1995.

Garriga, Carlos

“Orden jurídico y poder político en el Antiguo Régimen”, en Istor. Revista de Historia Internacional, 4: 16 (2004), pp. $13-44$.

González Navarro, Moisés

“La Ley Juárez", en Historia Mexicana, Lv:3 (230) (ene.-mar. 2006), pp. 947-972.

Gutiérrez, Blas José

Leyes de Reforma, México, Imprenta de Miguel Zornoza, 1870 , t. II, Parte II.

GutiérRez, José Marcos

Adiciones a la Librería de Escribanos, Abogados y Jueces, Madrid, Imprenta de la viuda de Villalpando, 1829.

Práctica forense criminal, primera edición mexicana adicionada, México, Imprenta de Juan R. Navarro, 1830.

Hamnett, Brian

Juárez, Nueva York, Longman, 1994.

Ibarra, Ana Carolina

El clero de la Nueva España durante el proceso de independencia, 1808-1821, México, Universidad Nacional Autónoma de México, 2010. 
Iglesias, Román y Marta Morineau

"La causa contra el padre Arenas, México, 1827", en Anuario Mexicano de Historia del Derecho, 8 (1996), pp. 189-197.

Jalisco

Jalisco, testimonio de sus gobernantes, 1826-1879, investigación, compilación y notas de Aída Urzúa y Gilberto Hernández, Guadalajara, Gobierno de Jalisco, 1987, t. I.

JuÁrEz, Benito

Antología, México, Universidad Nacional Autónoma de México, 2007.

Lira, Andrés

"Jurisdicción eclesiástica y potestad pública en México, 18211860”, en Casas y Mijangos (coords.), 2014, pp. 255-273.

"La actividad jurisdiccional del virrey y el carácter judicial del gobierno novohispano en su fase formativa", en BARRIOs (coord.), 2004, pp. 299-318.

López González, Georgina

La organización para la administración de la justicia ordinaria en el Segundo Imperio. Modernidad institucional y continuidad jurídica en México, México, El Colegio de México, Universidad Autónoma Metropolitana, 2014.

Lorente, Marta (coord.)

De justicia de jueces a justicia de leyes: hacia la España de 1870, Madrid, Consejo General del Poder Judicial, 2007.

Memoria

Memoria del Ministerio de Justicia y Negocios Eclesiásticos de la República Mexicana, presentada por el Secretario del Ramo a las Cámaras del Congreso general, en cumplimiento del artículo 120 de la Constitución Federal, y leída en la de Senadores el día 12, y en la de Diputados el día 20 de enero del año de 1832, México, Imprenta del Águila, 1832. 
Memoria en que el Gobierno del Estado Libre de México da cuenta al Congreso Constitucional sobre los ramos que han sido a su cargo, México, Imprenta del Águila, 1831.

Memoria en que el Gobierno del Estado Libre y Soberano de México da cuenta al Primer Congreso Constitucional de todos los ramos que han sido a su cargo en el año económico corrido desde el 16 de octubre de 1826 hasta el 15 del igual mes de 1827, Tlalpan, Imprenta del Gobierno, 1828.

Memoria que en cumplimiento del artículo 120 de la Constitución Federal de los Estados-Unidos Mexicanos, leyó el Secretario de Estado y del Despacho universal de Justicia y Negocios Eclesiásticos, en la Cámara de diputados el día 8, y en la de senadores el día 10 de enero de 1828, sobre los ramos del Ministerio de su cargo, México, Imprenta del Supremo Gobierno, 1828.

Memorias de la Secretaría de Justicia, estudio preliminar y compilación de José Luis Soberanes, México, Universidad Nacional Autónoma de México, 1997.

MORICONI, Miriam

Política, piedad y jurisdicción. Cultura jurisdiccional en la Monarquía Hispánica. Liébana en los siglos XVI-XVIII, Rosario, Prohistoria ediciones, 2011.

Munguía, Clemente de Jesús

Defensa eclesiástica en el obispado de Michoacán desde fines de 1855 hasta principios de 1858, México, Imprenta de Vicente Segura, 1858, t. I.

O'Gorman, Edmundo

Historiología. Teoría y práctica, México, Universidad Nacional Autónoma de México, 1999.

Ornelas Hernández, Moisés

"La dimensión parroquial de las tensiones Iglesia-Estado en el obispado de Michoacán, durante la primera mitad del siglo xix”, en Casas y Mijangos (coords.), 2014, pp. 79-110. 
Otero, Mariano

Obras, recopilación, selección, comentarios y estudio preliminar de Jesús Reyes Heroles, México, Porrúa, 1995, t. I.

Peña y Peña, Manuel de la

Lecciones de práctica forense mejicana, escritas a beneficio de la Academia Nacional de Derecho Público y Privado de Méjico, México, Imprenta de Juan Ojeda, 1836, t. II.

Reyes Heroles, Jesús

El liberalismo mexicano, México, Fondo de Cultura Económica, 1982, 3 tomos.

Roeder, Ralph

Juárez y su México, México, Fondo de Cultura Económica, 1984.

Romero Gil, José H.

Prontuario alfabético de legislación y práctica, México, Imprenta de la Voz de la Religión, 1853.

Rubial, Antonio et al.

La Iglesia en el México colonial, México, Universidad Nacional Autónoma de México, Benemérita Universidad Autónoma de Puebla, Ediciones de Educación y Cultura, 2013.

Scardaville, Michael C.

"Los procesos judiciales y la autoridad del Estado: reflexiones en torno a la administración de justicia criminal y la legitimidad en la ciudad de México, desde finales de la colonia hasta principios del México independiente", en Connaughton (coord.), 2003, pp. 405-422.

Solares Robles, Laura

Bandidos somos y en el camino andamos. Bandidaje, caminos y administración de justicia en el siglo XIX. 1821-1855. El caso de Michoacán, Morelia, Instituto Michoacano de Cultura, Instituto de Investigaciones Dr. José Ma. Luis Mora, 1999. 
SPECKMan, Elisa

Crimen y castigo. Legislación penal, interpretaciones de la criminalidad y administración de justicia (Ciudad de México, 1872-1910), México, El Colegio de México, Universidad Nacional Autónoma de México, 2002.

TAmayo, Jorge L.

Benito Juárez. Documentos, discursos y correspondencia, selección y notas de..., edición digital coordinada por Héctor Cuauhtémoc Hernández Silva, México, Universidad Autónoma Metropolitana-A, 2006.

Traslosheros, Jorge E.

Historia judicial eclesiástica de la Nueva España. Materia, método y razones, México, Universidad Nacional Autónoma de México, Porrúa, 2014. 